\title{
Assets-Based Learning Abroad: First- Generation Latinx College Students Leveraging and Increasing Community Cultural Wealth in Costa Rica
}

\author{
David Wick \\ Middlebury Institute of International Studies at Monterey \\ Tasha Y. Willis \\ Jacqueline Rivera \\ California State University, Los Angeles
}

\section{Evelyn Lueker}

University of California, San Diego

\section{Maria Hernandez}

California State University, Los Angeles

\begin{abstract}
:
This qualitative study counters deficit narratives about first-generation Latinx students by exploring multiple forms of community cultural wealth (CCW; Yosso, 2005) that 25 students leveraged and increased during service activities and homestays in Costa Rica. Through longitudinal data and with $\mathrm{CCW}$ as a conceptual framework, three key themes emerged. First, students were able to leverage their linguistic and familial capital to connect quickly and meaningfully with locals. Additionally, students drew upon their linguistic, familial, aspirational, and resistant capital while abroad to deepen their engagement. Finally, student interaction with their forms of CCW appeared to deepen their bicultural identities, strengthen their resistance to injustice, and instill a strong desire to inspire other Latinx students to pursue international education. Implications for practice include an integrated approach to recognizing and rewarding students' CCW-related capital in the advising, application and preparation processes. Implications underscore the importance of using strengths-based pedagogies in the design of education abroad programs.

\section{Introduction}

High impact educational practices, such as study abroad, have been promoted as approaches to increasing and broadening postsecondary student engagement and success (Kuh, 2008). Indeed, among other benefits, study abroad has been linked to intrapersonal (Engle, 2017; Teranishi \& Hannigan, 2008), interpersonal, and intercultural communication growth (Chieffo \& Griffiths, 2004; Mapp, 2012; Stebleton, Soria, \& Cherney, 2013). Positive correlations have also been noted between study abroad participation and academic persistence and success (Sutton \& Rubin, 2010; Raby,
\end{abstract}


Rhoads, \& Biscarra, 2014) and more recently with career skill development (Farrugia \& Sanger, 2017). These findings have fueled concerns related to persistent underrepresentation by students of color and calls for more participation by first-generation college students (Engel, 2017). At the same time, expanding and diversifying access without attention to clarifying goals and designing programs with underrepresented minority students and first-generation college students in mind would be misguided. Additionally, the voices of students of color and, even more so, first-generation college students have been largely absent from research in this area. These concerns have led us to seek data on the nature and benefit of the study abroad experience for underrepresented students. Through this research, we hope to identify elements of a critical pedagogy that can be utilized to increase the consciousness-raising (Freire, 1986) impact of these experiences.

A small body of literature has begun to suggest that students of color have distinct, and often challenging, experiences during international study programs (Landau \& Moore, 2001; Willis, 2016). Some researchers also see potential value in these programs that is different from the benefits that have been widely documented for White, female students, who make up the majority of study abroad participants (Institute of International Education [IIE], 2018). Students of color may engage with and benefit from study abroad differently as suggested in research by Jackson (2006), Wick (2011), and Willis (2012), who shifted the focus, reflecting related themes of "empowerment," "agency," and "self-actualization," respectively. Further, students' real and perceived relationships to a host culture, often described as heritage destinations (e.g., U.S. Latinx students studying in Latin America or Spain), also add complexity to the experiences that students of color have abroad (Morgan, Mwegelo, \& Turner, 2002; Willis, 2015). Further, some have noted that benefits for students of color who study abroad often include heightened commitments to working toward equity and justice at home and abroad (Willis et al., 2019).

Yosso's (2005) Community Cultural Wealth (CCW) framework offers an asset-based lens through which to view students who are otherwise often viewed from deficit perspectives. Her model captures the assets and strengths that students of color bring with them into educational environments, offering educators the opportunity to consider how to assist students in building upon these strengths for further success. The model highlights six forms of cultural wealth or capital: a) aspirational, b) linguistic, c) familial, d) social, e) navigational, and f) resistant. From a CCW perspective (Yosso, 2005), we expect that the value and benefits of study abroad may instead vary depending upon student identities and host cultures. Raising questions about the nature and value of study abroad for Latinx first-generation college students in Costa Rica has allowed us to reexamine our approach to design and delivery of study abroad and to describe distinct strengths and benefits for historically underserved students based on the host context.

\section{Literature Review}

To ground our research on the population we set out to explore-first-generation collegegoing Latinx students studying abroad in Latin America-we examined the existing literature. We found that only one study on this population has been published (Willis, Wick, Han, Rivera, \& Doran, 2019). Thus, our literature review necessarily spans several areas: a) first-generation students in higher education (with an emphasis on strengths-based studies), b) first-generation students in education abroad, c) identity exploration study abroad literature (often referred to as heritageseeking), d) critical pedagogies (strengths-based), and e) Latinx college students. 


\section{First Generation College Students}

Research on first-generation college students has tended to focus on the varied challenges they encounter as they enter higher education. For example, Pascarella, Pierson, Wolniak, and Terenzini (2004) resolve that first-generation students are less likely to continue past their first year of college, enter graduate school, or be engaged in extracurricular activities, which holds implications for their academic and social development. Padgett, Johnson, and Pascarella (2012) report that firstgeneration students feel intimidated and uncomfortable interacting with faculty. Stephens, Fryberg, Markus, Johnson, and Covarrubias (2012) posit that many first-generation students experience a "cultural mismatch" between the dominant culture of higher education that primarily values independence, and their sense of self, which is largely grounded in values of interdependence and relationships. DeRosa and Dolby's (2014) work identifies that students felt stigmatized related to being lower-income first-generation college students.

However, strengths-oriented research documents the unique assets and capacities of firstgeneration college students, challenging the dominant deficit and institutional barriers narratives of earlier literature. For example, though they may face some common barriers as a result of being the first in their families to attend college, first-generation college students' strengths often include drive and independence (Martin, Galentino, \& Townsend, 2014), which contribute to their success. Jehangir, Williams, and Jeske (2012) note that these students, as the first members of their families to attend college, are afforded special status and respect. Jehangir et al. offer evidence that firstgeneration students who experience marginalization and oppression develop self-authorship earlier in their lives and are also often more adept at managing the ambiguity of unknown environments than their non-first-generation peers. Kouyoumdjian, Guzmán, Garcia, and Talavera-Bustillos (2017) use Yosso's (2005) CCW framework to document the variety of forms of capital first- and secondgeneration Latinx college students bring to their campus experience which support them in the higher education context.

\section{First-Generation Students Studying Abroad}

Given the common default to a deficit view of students of color (Ladson-Billings, 2014) and first-generation college students, it is perhaps not surprising that finding strengths-based literature on education abroad among these populations is rare. Our search only identified two studies (both dissertations) that have used asset-based frameworks for analysis, recognizing strengths that firstgeneration students leverage as they navigate education abroad programs. Rausch's (2017) sample $(n=35)$ included 12 Latinx students and the author developed the first-generation strengths theory, noting themes of resilience, independence, drive, and navigational capital that participants possessed. Similarly, Waldrep's (2017) work posits that participants drew upon their inherent navigational capital (Yosso, 2005), which facilitated their ability to participate in education abroad and supported them in coping in unfamiliar terrain in other countries. Research on students' racial and ethnic identity have also been found to impact the ability to participate in study abroad, student experiences, and development.

\section{Identity Exploration}

Some sojourners may have or may perceive cultural, ethnic, or racial connections to their host destinations. Education abroad practitioners and researchers commonly characterize such students as "heritage seekers," whether heritage and identity exploration are among students' stated goals. 
Two such heritage studies reflect a common theme in the research-unmet expectations. Barlow (2007) discovers that second-generation Indian students from Canada visiting India expected to have positive interactions because of their anticipated familiarity with the culture. However, many experienced frustration at their lack of proficiency in the local dialect and with the expectations that locals had for them. Several Black U.S. students struggled with the experience of "looking black [sic]" but being read as "white" by their South African hosts due to their nationality, which unexpectedly seemed to supersede their racial identity in that context (VeLure Roholt, \& Fisher, 2013). Aspects of personal identity such as gender, race, ethnicity, and nationality are significant in shaping students' experiences abroad and prompted personal development despite confronting those students with unsettling realities.

Peer-reviewed studies involving Latinx students in Latin America, Spain, or the African Diaspora are rare, and have more often focused on ethnic identity development (Teranishi, 2007; Teranishi, \& Hannigan, 2008), language development (Shedivy, 2004), or in one case, social work professional identity development (Willis, Wick, Bykowski, Doran, Li, \& Tran, 2019). One dissertation study featured primarily Mexican American students studying in Latin America or Spain (Guerrero, 2006) while another dissertation (Raymondi, 2005) examines Dominican American students in Senegal. This gap propels the current study, which offers insights into the ways that Latinx students' preexisting CCW (Yosso, 2005) mediates their experiences in Costa Rica and shapes their learning outcomes, with implications for program design considerations that take these strengths into account.

\section{Critical Pedagogies: Strengths-Based}

Strengths-based pedagogies present one approach to countering deficit narratives and supporting student success. Strengths-based education (SBE) is an approach used in both higher education and K-12 settings that counters what Anderson (2005) refers to as the "deficit remediation education model" (p.181), which is often used with the intention of helping students catch up to higher performing peers. Rather than assuming and focusing on students' areas for development, SBE requires educators to self-reflect on their own strengths as instructors while simultaneously helping students explore and refine their inherent talents into strengths through knowledge and skill acquisition. Anderson (2005) and Lopez and Louis (2009) posit that students inherently possess talents and strengths that educators should foster through the discovery and implementation of appropriate learning activities. Lopez and Louis (2009) identify five principles of SBE, which are (a) measurement of educator and student strengths, (b) individualization capitalizing on each student's unique strengths, (c) networking relationships with others who help students see their own strengths, (d) deliberate application of strengths both in and outside of the classroom, and (e) intentional development of strengths through strategic and focused practice. These two conceptual articles are similar to a mixed-methods study $(n=1,421)$ by Soria and Stubblefield (2015) that identifies a positive correlation between student strengths awareness and both their sense of

belonging on campus and their retention. Qualitative analysis suggests that strengths initiatives on campus facilitate first-year students' self-confidence and self-awareness, and even fosters peer relationships, factors thought to contribute to engagement, belonging, and retention. SBE is suggested as an important approach for education abroad, especially among underrepresented 
students (Trujillo, 2017). By building on students' strengths through pedagogical decisions, their experiences and learning outcomes abroad can be enriched and maximized.

Latinx college students.

Latinx students do not obtain educational degrees on equal footing to more privileged students (Villalpando, 2004). Latino critical race theory (LatCrit) posits that they face racialized practices, policies, and structures that create barriers along the educational pipeline (Solórzano, Villalpando, \& Oseguera, 2005). Villalpando (2004) further notes that intersecting aspects of their identities such as language, generational status, gender, sexuality, and class combine with racial discrimination within and outside the classroom. These complex, multidimensional social statuses and experiences require university personnel to consider ways to effectively support them on campus.

Two educational practitioner-scholars address these concerns through the use of culturally responsive pedagogies grounded in strengths-based and relationship-centered philosophies. Valenzuela's theory of subtractive schooling (1999) notes that school structures remove cultural resources from Latinx students, stripping them of their inherent "culture, language and communitybased identities" (2002, p. 236). She argues for an additive schooling model to counter these losses, which requires intentional fostering of authentic, caring relationships between students and educators. Similarly, Rendón suggests we must validate Latinx students' lived experiences through our teaching approaches (1994). She further develops her work, indicating we must use what she refers to as "sentipensante (sensing/ thinking) pedagogy" to support students in transcending limiting views about themselves on their path to liberation and becoming agents of social change (2009).

Thus, it is our belief that to maximize the benefit of study abroad for first-generation Latinx students, their experiential knowledge and lived experiences should be viewed as assets, sources of empowerment, and strengths that can serve them well abroad. This led us to apply Yosso's CCW (2005) model to our analysis.

\section{Methodology}

Aims

We approach this research with two related goals. These international social work education programs and the related research project are intended to advance knowledge while also engaging in socially just praxis. This means that throughout the teaching and research process we are reflecting upon our processes with our students in order to take more informed and appropriate action to support learning and liberation (Freire, 1986; Kolb, 1984). We have elected to focus on two underresearched groups in education abroad literature, Latinx and first-generation college students, which happen to co-exist on our campus in large number. We designed this research to provide insights into the following questions:

1. How do the inherent strengths that first-generation college U.S. Latinx social work students bring to international service opportunities in Costa Rica impact their experiences abroad?

2. How do participants' assets and growth relate to the Yosso's (2005) CCW framework?

Site 
The School of Social Work at "X State University" (XSU), an Hispanic Serving Institution with 63\% Latinx population, offers Bachelor's and Master's degree programs. Approximately 150 bachelor of social work (BASW) students graduate annually, with many continuing on to the MSW program, where approximately 250 students a year prepare "to assume leadership roles in professional practice ... [and to] . . analyze, intervene, evaluate and advocate with diverse, underserved and oppressed clients and communities." Study abroad is only recently expanding in XSU. Prior to 2016-2017, fewer than 50 XSU students university-wide participated in education abroad courses.

Between 2014 and 2016, two types of international service opportunities were available for social work students. Both leveraged students' Spanish-language skills in professional service settings and homestays. During that time, MSW students had access to a 6 -week (40 hours per week) graduate-level, non-credit bearing summer internship. In 2015, BASW students could enroll in a 3unit service learning course through which they spent four hours daily at their assigned service learning projects. The Costa Rican host university's extension department coordinated both of these opportunities for XSU students. Specific projects varied year to year based on the needs of the community sites and the local staff willing to supervise visiting students. In 2014, the graduate students each had their own sites and supervisors. In 2015 and 2016, both graduate and undergraduate groups worked on team projects with at least one other peer from their program. Supervising site staff may or may not have been professionally trained social workers and students received minimal information about their sites ahead of time, which created some anxiety for them as learners. To reinforce social work frameworks, U.S. faculty served as the social work bridge through weekly or daily reflections, as is commonly the case in US-based field seminars.

\section{Participants}

Eighty-four percent of participants reported being the first generation in their family to attend college. Fourteen MSW internship participants had previously completed a yearlong MSW internship and demonstrated sufficient Spanish language proficiency to work directly with clients for six weeks in the summer of 2014, 2015, or 2016. Eleven undergraduates were from a 2-week service learning course in summer 2015. Six of these were current BASW students, one was entering the MSW program, and four came from other human service fields. All identified as having Latin American heritage and all but one had advanced or intermediate Spanish. Most expressed the ambiguity of ethnicity, race, and nationality given their parents' or their own immigration journeys from Mexico or Central America. We note that in order to represent the nuanced and self-declared pan-ethnic identities of our participants we intentionally elected to use the term Latinx in our writing, as it was coined in the US to present greater gender inclusivity than is implied by terms such as Latino or Latina (Lozano, A., 2015; Ramirez \& Blay, 2016; Scharrón-del Río \& Aja, 2015). Thus, the final sample combined for this study included 25 Latinx students.

Graduate students were required to have sufficient language proficiency to serve clients as they interned eight hours daily on weekdays. Undergraduates had no specific proficiency requirement though most possessed fairly strong Spanish language skills and tested into the advanced level for their four hours daily of Spanish language classes. Both undergraduate and graduate students stayed with local homestay families and found the language and cultural differences stimulating and yet relatively easy to navigate. Due to the similarities between the service-oriented programs and profiles 
of students ethnically and linguistically, upon analyzing data from both undergrad and graduate students, we decided to report on the findings jointly.

Table 1. Self-reported participant demographics.

\begin{tabular}{|c|c|c|c|c|c|}
\hline Ethnic Identity & $\begin{array}{l}\text { Mexican/ } \\
\text { Mexican American/ } \\
\text { Chicana }\end{array}$ & $\begin{array}{l}\text { El Salvador/ } \\
\text { Salvadorian }\end{array}$ & Nicaraguan & $\begin{array}{l}\text { Mexican and } \\
\text { Guatemalan }\end{array}$ & $\begin{array}{l}\text { Mexican } \\
\text { and } \\
\text { Japanese }\end{array}$ \\
\hline & 20 & 2 & 1 & 1 & 1 \\
\hline Gender & $\begin{array}{l}\text { Males } \\
2\end{array}$ & $\begin{array}{l}\text { Females } \\
23\end{array}$ & & & \\
\hline Age & $\begin{array}{l}18 \text { to } 21 \\
3\end{array}$ & $\begin{array}{l}22 \text { to } 30 \\
19\end{array}$ & $\begin{array}{l}31 \text { to } 40 \\
2\end{array}$ & $\begin{array}{l}41 \text { to } 50 \\
0\end{array}$ & $\begin{array}{l}51 \text { to } 60 \\
1\end{array}$ \\
\hline $\begin{array}{l}\text { First-Generation } \\
\text { College }\end{array}$ & $\begin{array}{l}\text { Not sure } \\
3\end{array}$ & $\begin{array}{l}\text { No } \\
1\end{array}$ & $\begin{array}{l}\text { Yes } \\
21\end{array}$ & & \\
\hline $\begin{array}{l}\text { Self-Reported } \\
\text { Language Level }\end{array}$ & $\begin{array}{l}\text { Basic } \\
1\end{array}$ & $\begin{array}{l}\text { Intermediate } \\
8\end{array}$ & $\begin{array}{l}\text { Advanced } \\
16\end{array}$ & & \\
\hline
\end{tabular}

\section{Methods}

Researchers collected data before, during, and after four study abroad programs (three 6-week graduate internships and one 2 -week undergraduate service learning course). Post-program data was collected one month after each program and six to nine months later as we intended to maximize contact with students for the research process itself (Rossman \& Rallis, 2016) and also as part of our high-intervention approach to stimulating their reflection (Bathurst \& LaBrack, 2012; Zull, 2012). Researchers adapted focus group protocols and in-country journal prompts to meet the differing needs and realities of the undergraduate and graduate students. MSW students also participated in individual interviews at all three points in time. Axial coding using the CCW (Yosso, 2005) framework revealed similar themes across all of these data sources (Saldaña, 2016) leading us to merge our analyses of these programs. In order to triangulate these findings, we reviewed and integrated faculty observations of participants in our analysis.

\section{Instrumentation}

High intervention programming (Bathurst \& LaBrack, 2012; Zull, 2012) does not assume an immersion experience automatically results in substantive gains. This was a guiding principle in our research and program design; we used structured participant reflection at many points in time to stimulate and therefore deepen participant self-awareness (Urdang, 2010).

Graduate intern interviews.

MSW participants took part in individual interviews before departure, within one month of program completion, and six to nine months later. We intentionally conducted the second and third interviews prior to conducting focus groups to avoid influencing individual reflections with groupthink. The pre-departure protocol was aimed at understanding participants' ethnic, national, and gender identities and beliefs about gender roles. The 1-month post-program protocol targeted 
how participant identities may have been influenced by their experiences in Costa Rica and conversely how these identities might have shaped their experiences. The 6-to-9-month postprogram interview protocol echoed the 1 -month protocol and was created to gauge sustained learning.

Reflective journals.

We designed journal prompts to stimulate reflection, support meaning making related to initial impressions, and process experiences related to the aims of each program. Students also submitted between three and six journal entries electronically during their programs in response to structured questions.

Post-program focus groups.

Research assistants conducted post-program focus groups within a month of program completion and between six to nine months post-program. Our underlying assumption was that the opportunity to reflect with peers would allow all students to deepen their learning from their experience abroad as they heard the varied experiences and perspectives of others who might be at different stages of their personal and professional journeys. Protocols furthered inquiry into participants' personal and professional development. The 6-to-9-month post-program focus groups sought to examine if gains documented in the 1-month post-program groups were sustained, or perhaps deepened, through the end of the academic year (Bathurst \& LaBrack, 2012; Zull, 2012).

\section{Analysis}

Our analytic framework incorporated Yosso's CCW model (2005), grounded in critical race theory, which acknowledges the "centrality of experiential knowledge" and the stories of people of color as marginalized groups (Solórzano, 1998). CCW counters a dominant narrative-that Latinx students arrive lacking foundational cultural capital necessary for success in higher educationinstead asserting that they arrive with at least six forms of cultural capital: aspirational, familial, linguistic, navigational, social, and resistant (Yosso, 2005).

We approached qualitative analysis with multiple rounds of coding based on the grounded theory coding canon (Saldaña, 2016), although the intent of this research was not development of theory. We conducted first cycle coding in waves over several years, reflecting the iterative nature of qualitative research and the constant comparative method (Lincoln \& Guba, 1985). Research assistants worked in teams each year to open code three transcripts and to generate initial concept code lists, which we then refined under the Principal Investigator's (PI) supervision to create a final concept code list. The teams then uploaded these lists into Dedoose, an online qualitative software, to facilitate axial coding (Saldaña, 2016) to identify connections to the CCW model. Throughout the analysis process, we utilized peer debriefing (Onwuegbuzie \& Leech, 2007) with research assistants and several faculty colleagues to enhance trustworthiness. This analysis revealed remarkably similar themes across all participants, despite the inherent cognitive differences between undergraduate and graduate levels of study, which led us to examine the undergraduate service learning and the graduate internship results together in this study.

\section{Ethics and Trustworthiness}

The PI approached this work in a deliberate and participatory manner in order to respond to the power differential and ethical issues implicit in the dual roles she and the participants held with 
each other. Students in the 6-week MSW internship program were not receiving academic credit for their internship (co-led by the PI). In contrast, the undergraduate experience, also co-led by the PI, did yield academic credit. However, to emphasize the voluntary nature of participation in the research study, MSW and BASW research assistants were the primary recruiters and conducted most interviews and other data collection. This approach underscored the message that participation had no bearing on academic standing in any course. Research assistants had no teaching affiliations in the school and they were assigned interviewees whom they did not know and who were not in their cohort. Further, the undergraduate course ended and grades were submitted by the time the postprogram and follow-up data were collected.

As a research team, we are cognizant of our differing positionalities as a result of our intersectional identities, including race, ethnicity, class, gender, age, spirituality, and even disciplinary backgrounds. Three of us are non-Latinx (we identify as Black, White, and White Jewish), while two of us identify as Salvadoran-American and Mexican-American. Two of us were the first in our families to attend college, and we span three decades in age. Three of us hold master's degrees in social work, one has completed her master's degree in international education management, two of us hold EdDs in higher education leadership, and one of us holds a $\mathrm{PhD}$ in social welfare. While four of us are grounded specifically in critical race theory as a key lens through which we view our world and work, we all converge in our asset-based perspectives in our respective fields of social work and education. We see our collective positionalities as having strengthened our peer-debriefing process and our final product as we have leveraged our diversity to challenge ourselves to ensure we center equity, inclusion, and credibility in our methods.

\section{Findings}

The data suggest three key findings related to the interplay between CCW and the firstgeneration Latinx students who participated in this study. First, students were able to leverage their linguistic and familial capital in meaningful ways to connect with their hosts in this context. Additionally, the data present insights into how students drew upon not only their linguistic and familial capital but also their inherent aspirational and resistant capital while abroad. Finally, ways that students interacted with their forms of CCW appeared to deepen their bicultural identities, strengthen their resistance to injustice, and instill a strong desire to inspire other Latinx students to pursue international education experiences.

\section{Leveraging Linguistic and Familial Capital}

Study abroad students commonly discuss the phenomenon and power of getting outside of their comfort zones (Vande Berg, Paige, \& Lou, 2012). Even students who study in what are traditionally labeled as heritage destinations often describe disorienting experiences due to cultural differences and language barriers. However, participants in this study overwhelmingly expressed being warmly welcomed, being able to blend in fairly well, and getting easily connected. This appears to have contributed to an element of comfort while abroad, which may have contributed to their ability to push their linguistic and professional learning on the program.

The warmth of the students' welcome may have been due to the linguistic similarities between Costa Rican Spanish and Spanish often spoken in their U.S. contexts, reflecting the fact that Spanish language fluency was a requirement for the graduate interns and strongly encouraged for the 
undergraduate service learning course. Of note is that the Latinx students, despite the fact that they were not from Costa Rican communities in the United States, were able to leverage not just their linguistic wealth but also their familial wealth in order to connect with the host community quickly and meaningfully.

Throughout their experiences participants reported that their easy integration was due to their advanced and intermediate Spanish language skills combined with the many values, norms, communication styles, and cultural references that they shared with their Tico (affectionately used idiomatic term by and for native Costa Ricans) host families and professional colleagues. Jewels represents multiple voices from the group in her initial in-country journal entry: "When I first interacted with people in Costa Rica, I felt I was one of them. Since it initially reminded me of Mexico, I did not feel much difference. I felt the warmth and welcoming of the people." Though this reflects the first impressions of most participants, it is perhaps not surprising given the student demographics and host community. In Quetzali's journal, she reflected:

My ethnic background [Mexican] has assisted me in having a better understanding of how and why do people in Costa Rica behave in a certain way. For instance, my homestay mother is very religious and I feel that my religious background [and] being Mexican has definitely assisted me in building a strong connection with her.

However, these reflections from early in participants' stays do highlight a potential risk of education abroad. Some participants, perhaps depending upon their relative level of intercultural sensitivity (Hammer, Bennett, \& Wiseman, 2003) prior to arrival, may not derive as much intercultural nuance as is needed to fully realize the potential gains of their cross-cultural experience. Instead, they could complete the program having reified their preconceived notions and superficial understandings about a culture instead of seeing the more varied texture that lies below the surface. In light of this concern, we reviewed reflections from other participants at later points in time. We noted that students were in fact able to draw upon knowledge of their families to ground them in a deeper understanding of the diversity between Latinx cultural groups and experiences. For example, in the 6-month post-program focus group, Xochitl explains it in this way:

So it just made me reflect a little bit on how maybe their experiences are similar with family members that have also come to the United States and have integrated and have assimilated into the culture as well. So it just made me realize that the different levels of experiences that we had even within the same ethnicity or race can make us be very different or identify very differently based on our experiences.

These participants' insights about their proximate cultural knowledge based on their ethnic heritages yielded valuable information about their inherent strengths and capacities as U.S. Latinx students living and serving in Costa Rica. Xochitl's heightened awareness of the diversity between different ethnic groups that are described by the term Latinx suggests intercultural learning.

In addition to cultural familiarity, most participants noted that their Spanish language abilities facilitated relationship building with their hosts (homestay families, placement staff, clients, etc.) and allowed them to be genuinely of service in their placements. For example, in the 1-month postprogram focus group, Janira expressed that her host mother was: 
really happy and that's why she enjoyed taking students from this program, in particular, because she loves how they were Latinos, and we speak the language. Again, it's easier to form that bond. She had no issues communicating with us or anything. That definitely helped.

Blending in linguistically was not just a matter of comfort and ease, but it also served to make students more productive and useful in their international service placements. In her in-country journal, Esmeralda explained, "Having the luxury of a high level of Spanish has made my work with the organization staff, children and families much easier." Jewels pointed out, in the 1-month postprogram focus group, that she and other peers received feedback from their placements that their pre-existing language capacities were rare for international interns and were highly valued: "I think most of us ... heard that they [placement staff] would constantly tell us . . it was a different experience just because they're always used to having interns [who] don't speak Spanish." These comments were echoed in informal discussions that program facilitators, including Author One, held with homestay families and during service placement site visits with host supervisors. They noted the marked difference it made to have students who were bilingual and, from their Costa Rican perspective, bi-cultural.

As in this last exemplar, other participants routinely expressed the comfort of being welcomed and feeling connected to their experiences as a result of perceived similarities shared between their own Mexican or Central American culture and the Costa Rican host culture. It is not clear if all participants absorbed the different nuances but they did seem to draw upon the similarities related to family values, religion, gender norms, language, pop culture, hospitality, communication style, etc., which served as a foundation of internal strength for sojourners. As all participants in this study shared Latinx heritage and nearly all spoke Spanish fluently or almost fluently, they were favored both in their homestays and placements. Hosts in both contexts were used to non-Latinx guests and interns who were generally more challenging to incorporate into daily life and work. Though these assets are not necessarily unexpected, the ways that participants used and built upon these strengths was of particular interest to us as it helped us to better understand how learning was happening for students while abroad.

\section{Process of Change}

"It changed my life" is a common statement among students who have participated in international study experiences (Berdan, Goodman, \& Taylor, 2013). Through this research we gained insights into how the first-generation Latinx students on these programs developed through their international experiences. Specifically, in examining how students were growing and changing, we noticed that moments when participants drew upon their familial, linguistic, and resistant capital appeared to be at the core of student learning and growth. In many cases these incidents allowed for an examination of the value of the specific forms of CCW and contributed to a recognition of the concrete learning benefits that accompanied them. The participants' emerging awareness of CCW strengths appears to have allowed them to build upon their strengths and to utilize them in more contexts and ways. 
How linguistic and familial capital propelled reflection.

Reconceptualizing the meaning and value of ethnic identity and language skill was commonly described by participants and appears to carry many advantages. Rosa defined three in one of her incountry journals:

Being a gringa [who] speaks Spanish in Costa Rica has some advantages and disadvantages. Advantage 1: . . . Because I can actually converse with them they want to show me their country, the food, art, dance, the kids, family. Advantage 2: Most people are helpful with directions and Uber drivers are extra charitable. Advantage 3: People don't see me as threat here, like they know I am here to help. It's not difficult to relate.

In many ways this excerpt underscores what we noted in the previous section about how linguistic and familial capital connected students to the local culture. The third advantage introduces a new element, that of Rosa's role in relationship to the Costa Ricans. She appeared to be noticing that, in addition to the linguistic and familial wealth that she possessed, her activity on the program and relationship to the local culture provided her with additional ways to connect and relate to herself.

Xochitl's in-country journal writings delved deeper into questions about national and ethnic identity and the ways that studying in Costa Rica created an opportunity to examine the interrelationships of these identities. She wrote:

I have always thought of myself as Mexican, . . . even though I have lived in Southern California practically all of my life. Nevertheless, as I reflected on my experience and the similarities/differences between my Mexican culture and that of the Costa Ricans, I have to acknowledge that my identity is also influenced by the American culture . . . there were things that I had to recognize that would be similarities between the Costa Rican culture and my Mexican culture, but which were not necessarily similarities between the Costa Rican culture and my own cultural experience as a Mexican who grew up in the US. This was something that I don't think I had given much thought to in the past and which brought me a new perspective about myself when I reflected upon it.

These linguistic and familial assets allowed participants such as Rosa to connect with locals and for Xochitl, and others, to reflect on their identities. The relative comfort and confidence that participants experienced related to linguistic and familial capital appeared to create a productive learning environment. For example, the ways that participants described their evolving understanding of their identities appeared to stem from a recognition of the value of linguistic and familial capital that they possessed. The comfort created by leveraging these forms of capital in an international context may have helped to create the context that students needed to examine questions of privilege and power.

Confronting privilege: necessary step in growth process or missed learning opportunities?

Some participants in this study, when confronted with the economic and social realities of their host country, recognized how privilege is a relative concept while others did so to lesser extents. Many wrestled with guilt and discomfort relating to their positionality in the world and relative to their Costa Rican counterparts. For example, Monica, in her 1-month post-program interview articulated: 
So it's like I feel like the thing that makes me feel guilty is that I almost feel spoiled. Even if I grew up with the family that had low income and we're probably looked down as the disenfranchised groups and the minority as a woman and a Mexican-American, but then I see these countries that they need so much and I'm kind of like, oh my gosh. Here I am thinking that I am low income, and I am, but I have a roof over my head and I have a bed and I have food, you know. And then you look at these people and it's like, they don't.

In a similar yet distinct vein, Yesenia recognized her U.S. privilege, in her 1-month post-program interview:

I knew that I had privilege, but Costa Rica really made me think about it a lot more, especially having kids say, "I want to go to the US" or "How's Disneyland? Have you ever seen that?" Then realizing, "Whoa. These kids might never have the opportunity to do that when I live 20 minutes away from there." Or these kids might not have the opportunity to go to school or go to university because they're so behind in their studies or because a lot of parents don't really feel it's necessary or they work.

Though both Monica and Yesenia observed the disparities between their own standards of living and access, Monica alluded more to systemic oppression as the result of her social identities. In contrast, though Yesenia noticed disparities, it is unclear whether she attributed the educational and employment barriers, and resulting social disparities in Costa Rica to larger questions of equity and justice. Yesenia's exemplar highlighted the potential missed learning opportunities in education abroad for some students if they are not guided to hone their critical reflection skills.

In addition to Yesenia's quote above, several of her peers' exemplars suggested that additional guidance and intervention might have better facilitated the process of change related to ethnic and national identity ambivalence. Elizabeth, Esmeralda, and Aurora appeared to also be developing a more nuanced relationship with their Americanness, but seemed to notice differences in power and privilege without questioning their role or the forces of oppression at play. Some of these reactions were connected to apparent discomfort with Costa Rican perceptions of the participants' reality or privilege as people from the United States. For example, Elizabeth shared in the 9-month postprogram focus group:

Even by the staff that we worked with, they thought that we were spoiled, rich, with money. We're none of that. [laughs]. We really had to paint a picture, "We grew up in communities such as this one...." They had an idea of us because we are from the United States ... that we have that privilege of travelling outside of our own sector or our own country. That really resonated the most and I could see how that is viewed because we do have those privileges . .. Yes we have this opportunity but it doesn't mean that I will have this opportunity later on.

Here, Elizabeth acknowledged her privilege yet also pointed out, even nine months later, the similarities they shared rather than the social disparity. A stronger emphasis during program debriefs by program facilitators on the relativity of power, privilege, and oppression may have helped participants make even more gains in critical consciousness. This relativity may have also been more effectively underscored had there been White peers present in their programs. The negotiation of identity and capital that we noted suggests that questioning aspects of identity is a vital process that 
allows participants to more powerfully leverage their linguistic and familial capital and propels increases in aspirational and resistant capital.

\section{Increased CCW from Study Abroad}

Findings suggest that in addition to leveraging existing forms of capital and experiencing the process of change, participants also experienced growth in multiple areas related to CCW. They gained heightened senses of their bicultural identities, which deepened and in some cases broadened their commitment to social justice, and participants became inspired to encourage other students from similar backgrounds to study abroad.

From 'betwixt and between' to 'both and': deepening of bicultural identity.

Most participants were born and raised in the United States and expressed the way in which the experience in Costa Rica compelled them to recognize and appreciate the complexity of their ethnic and national identities. Even those not born in the United States described heightened awareness of the influences of U.S. culture in combination with their family's ethnic heritage. Participants began, or continued, to explore the effects that Americanness had on them. They also deepened their relationship to, and interest in, their Mexican or Central American ethnic heritages and Spanish language, or both. Esmeralda, born in the United States, captured the general sentiment of many of her peers about the desire to dig into their own ethnic roots when she wrote in her journal, "This experience has increased my curiosity to learn more about my own culture and solidified my desire to live in Mexico for a year upon graduation." Similarly, Monica, born and raised in the United States by parents who immigrated from Mexico, seemed to experience personal identity gains related to her Mexican ethnic and linguistic heritage. In an earlier exemplar in the Confronting Privilege section, Monica could be described as wrestling with her liminal identity as a "brown-skinned" person who "look[s] Mexican," "clearly [wasn't] "American," yet held privilege relative to local Costa Ricans (1month post-program interview). By the time of her 6-month interview, she articulated gains this way:

[The program] impacted my sense of identity. I think it has given me more self confidence in what I could do. ... the fact that I took on a challenge that I felt was going to be very difficult, ... I know I speak Spanish, but again it was that self confidence that I was like "I can't speak professional Spanish like they do." But just going out there and saying "you know what, I'm just going to give it a try." And I did, and it helped me identify. Now I can say ... I actually say "yeah, I speak Spanish" or "yeah, I'm fluent in Spanish." Whereas before I was like, "yeah, I understand it or I speak it.” . . . it's helped me I guess identify that strength in myself.

Here, Monica seemed to be settling into owning her linguistic prowess, thus transforming her Spanish language skills, which are frequently devalued in the United States (Tran, 2010; Valenzuela, 1999), into a usable skill that underscores and heightens ethnic pride.

Beyond merely increasing ethnic or linguistic connection and pride (Teranishi, 2007), the existing familial and linguistic capital that students brought to their experience abroad appeared to have become resources that they could leverage more powerfully. For example, Xochitl's relationship to her Mexican and U.S. heritages became more nuanced through the experience of being in Costa 
Rica and actively engaging in reflection through the class and research study. At the time of her 6month post-program interview Xochitl concluded:

I have thought a lot more about how . . how having been born in Mexico but actually being raised in the United States has had a great impact in my life. Prior to this whole experience, and really reflecting on some of the questions that the study has been asking about ... I would just always say I am Mexican, we are very traditional, and culturally I am very identified with my Mexican culture. But, just having to think about some of these things a little bit more, I think I am able to recognize more how I have been impacted by it [American culture] ... [Participating in the class and study] has opened my mind a little bit more about how it is more complex than I ever really thought about it.

Similar to Xochilt, Denyris' exemplar from her 1-month post-program interview is striking. Born in Mexico, raised in the United States and participating in the Deferred Action for Childhood Arrivals [DACA] program, Denyris had disclosed in both her pre-departure interview and journal a complicated and contested relationship with the concept of Americanness. Notably, by the time of her 1-month post-program interview, Denyris recognized her American culture despite her contested status as an undocumented immigrant. She disclosed:

For some reason I actually feel more American. If that makes sense. Because I feel that maybe, even though my idea of Americans, they're all . . . it's not just the Caucasian White person. I think in the back of my head, there is always like, "Technically I'm not American." ... I kept just saying that but ... I have all the culture. I grew up here.

Living in Costa Rica for six weeks mediated Denyris' feelings about her immigrant status. Specifically, her time in Costa Rica fostered identity growth similar to Xochilt, Quetzali, Esmeralda, and others. They all found they could be both U.S. Americans and of a particular ethnic heritage, and that they can simultaneously experience marginalization in the United States while holding privilege relative to people in Costa Rica.

Affirmed resistance and aspiration to inspire.

As social work students, most participants in this study were likely aware of societal inequities and predisposed to notions of social justice in the United States. The opportunity to engage abroad however, particularly in a country with lower economic indicators, appears to have underscored their commitment to social justice causes, as expressed by Aurora when asked which professional social work competency was the most impacted by her experience in Costa Rica during the 1-month postprogram focus group:

Social justice. I've always been aware that there is [sic] injustices and economic injustice in other countries, but this Costa Rica experience where we just mainly live through it and see it, which makes me think about macro practice, and globalization, capitalism.

Similarly, Monica's comment during the 6-month post-program focus group reflected a heightened awareness of her privilege relative to those around her. She also went further, noting the need to figure out how to be an ally by taking action to assist, particularly as a social worker:

When you start seeing the little things that affect people at all levels, that's important to know, not just as a visitor, but as a citizen of whatever country you're from, and it's 
important to be able to relate the privileges you have as a citizen of your own country, but also how you could help other people and that's what social work is all about.

Quetzali echoed Monica's sentiments, during her 6-month post-program interview, taking these further into action when she decided to take on a leadership role related to international issues in her school of social work:

I mean especially the International Social Work Caucus, before last year I was like, "oh I don't have time for that" or "I don't really know what it is" and still like, I think a lot of people was [sic] like “. . . you should probably just worry about what's here rather than caring about what's happening outside the US" . . . but because of that, it's like "No, there are so many other issues!" .. . So, I would say that it was like mainly the trip, going to Costa Rica that kind of like influenced me into to getting into those like duties.

Though multiple participants attributed heightened interest in international issues to their experience in Costa Rica, Elizabeth's experience may have contributed to a different outcome. Elizabeth, like the majority of participants, was born and raised in the United States by parents with roots in Mexico. Like most others, she was surprised to be perceived as a gringa given her Mexican heritage, yet this contributed to her awareness of her privilege as a citizen of the United States as she explained in her 1-month post-program interview:

There's a lot of poverty. There's a lot of things that's going on but I think like-like it's good that I gained the experience there but there's a lot of work to be done here and even from where my parents are from.

Interestingly, in contrast to Quetzali, Monica, and Aurora, Elizabeth's experience in Costa Rica reinforced the urgency of social issues in her Los Angeles community and in Mexico, where her parents are from, rather than in Costa Rica or other international contexts.

Aurora's reflection in the 9-month post-program focus group was potent whether taken in a local or international setting: "I think this trip rather motivates me to rebel against sexism." In similar fashion, Paola expressed the following during a 1-month post-program focus group:

I also feel confident in the sense that I'm not scared to speak up. I think I was at one point. I was hesitant to say certain things, but now it's just like no, I'm not. It's more empowering for me to just speak up and also like just to ask for help.

Corresponding with the increased sense of empowerment and resistance, less than a year after participation, two participants, Quetzali and Xochitl, deepened their relationship to the program by taking roles as program assistants, leaders, or board members. This largely reflected their desire to create access to this transformative experience to students of similar backgrounds. Program involvement on these levels required ongoing and heightened commitment, reflecting personal and professional agency, leadership, and multiple other strengths including aspirational and navigational capital.

All participants noted that they were proud to have accomplished the feat of studying abroad in itself, and also expressed a sense of hope and possibility for the future as a result of their experiences in Costa Rica. For example, Mariel, in her journal suggested gains in her aspirations and capability as a leader: 
I was also very happy about the feedback people were giving to me about my attitude towards the project-some were shocked that I did such a great job as a leader and others told me they saw my growth and change from a shy timid girl to an open and strong woman that could help take charge of a project when they needed her.

Mariel's reflection underscored her individual agency and her capacity to navigate both the social service workplace and Costa Rican culture as she led an initiative to conduct an in-person survey on sexual harassment experienced by public transportation users.

Reflecting their awareness that study abroad is rare among many from their families and communities, multiple participants expressed a desire to be an inspiration to make the possibility into a reality for others from similar backgrounds. In the 1-month post-program focus group, Jewels articulated her hopes for inspiring members of her own family:

Just being able to show me, them and my family, that it is possible. . . . just . . . hoping to kind of make it more of a norm within my family as it's okay to do it. It's okay to go to college. It's okay to go abroad. If you were to go for a semester or a year, it's going to be okay.

Serving as an example for her family is clearly important to Jewels. In the same focus group, Paola expressed a desire to inspire more broadly, "I just want to be an example to other Latinos, because ... they just don't feel like they can do it." These exemplars reflect the nurturance of a "culture of possibility" (Yosso, 2005) in opposition to the numerous tangible and perceived barriers to study abroad experienced by many Latinx and first-generation college students. We noted that Quetzali and Xochitl's efforts to help strengthen the internship program through their own time and engagement for future students directly aligned with Paola's aspirations. Their efforts also served to further their own navigational capital as they practiced international program development and worked with nonprofit leadership and governance structures.

\section{Discussion}

We began this article by questioning the assumption that all students should study abroad and recommended attention to what and how students from historically underrepresented backgrounds are learning. We sought to address part of that gap with this study. Our findings suggest that the first-generation Latinx students who participated in this study increased their familial, linguistic, resistant, and aspirational capital through their experiences. Moreover, this research provided some insight into how students' pre-existing strengths increased their capacity to learn and facilitated their experiences of growth. Taken together, these findings provide additional rationale for changing support for students before, during, and after study abroad while also working to increase and diversify participation.

By utilizing Yosso's CCW framework (2005) this study underscores how first-generation college U.S. Latinx participants' pre-existing strengths relating to family and language serve as anchor points that they leverage to connect across national and cultural borders to deepen their learning experience. This is in sharp contrast to unmet expectations and identity-challenging experiences of students of color in heritage destination literature by Barlow (2007) and VeLure Roholt and Fisher (2013). In addition, our data not only suggest gains in a variety of CCW domains (i.e., familial, linguistic, resistant, and aspirational), but also help to explain bow those gains may have come to 
fruition. In alignment with strengths-based education, as described by Anderson (2005) and Lopez and Louis (2009), our findings counter an implicit deficit narrative about education abroad being an antidote to a presumed lack of cultural and social capital among first-generation college students, students of color and those who are both. Instead, we noted that program participants benefit from their international experiences perhaps precisely because of the unique strengths that they possess as first-generation Latinx college students and that program participation amplified those strengths even further. Important implications for practice can be drawn from the findings.

In terms of practice, there are several steps that we recommend program leaders implement in order to recognize and reward the CCW-related capital that first-generation Latinx students possess in the advising, application, and preparation processes. Selection processes for education abroad programs, scholarships, and fellowships often privilege academic performance through grades, formal foreign language study, and essay writing skills. Reframing application essays or videos in order to allow students to describe familial, linguistic, or aspirational capital can shift the focus of the application and selection process from a deficit- to a strengths-based approach.

In our study we noted that familial and linguistic capital were critical to student success. Drawing out these strengths throughout the pre-departure process can also re-center the experiences of marginalized students as vital skills for success in international settings. These types of approaches may serve to increase access and underscore capacity for success for historically underrepresented students. However, these approaches alone are insufficient in challenging the status quo if they are not combined with changes in teaching and learning during and after programs.

Practitioners need to adapt program structures during and after experiences in order to facilitate learning experiences that allow students to utilize and build upon their CCW. This research suggests that participants will examine their identities while abroad as they are confronted with different ways of being. Moreover, our research suggests that this examination of identity can greatly enhance learning. We believe that program leaders should expect this to happen and design programs to facilitate this internal journey. We noted that guiding students to examine their identity-related experiences abroad through reflective journals, interviews, and focus groups appeared to propel deep personal, interpersonal, and intercultural learning, as suggested by Bathurst and LaBrack (2012) and Zull (2012). Furthermore, we found that ongoing interactions in the form of interviews and focus groups after students returned to their home campus are essential to making meaning of international experiences. The ways that study participants affirmed their appreciation for their CCW suggest they had developed both pride and capacity to utilize these strengths in the U.S. context in ways they previously had not fully recognized. Perhaps more importantly, focusing on student assets throughout the process appeared to prepare them for domestic and international actions for social justice. Post-program, students appeared ready to examine how privilege and power function in the international context as they frequently wrote and talked about questions of justice, privilege, and power in their host community. For some this led to a nuanced understanding of the contextuality of social justice. Others simply noted that they had some advantages that locals did not have. We believe that stepping out of the U.S. context provided a unique crucible for examining these questions, and this research helped us to recognize that we could have done more to ensure that all participants honed their critical self-reflection skills. These could include more 
targeted journal prompts and group conversations designed to guide students to critically examine and make sense of what they were experiencing. For example, an additional journal prompt could directly encourage students to explore the complexity of their power and privilege as U.S. Latinx sojourners in the Costa Rican context. In addition, experiential learning debriefing models such as Bennett's describe, interpret, evaluate (DIE; 2015) or others can be used to help students remove judgement from cross-cultural experiences and thus prepare them for critical examinations of their agency related to global injustice.

\section{Conclusion}

Ultimately, we believe that these findings begin to address a gap in the literature by documenting the experiences of an underrepresented group in education abroad: Latinx firstgeneration college students. In 2016, Latinx students represented 39\% of students in U.S. higher education (de Brey, Musu, McFarland, Wilkinson-Flicker, Diliberti, Zhang, Branstetter, \& Wang, 2019 ) and $10.2 \%$ of U.S. study abroad students (IIE, 2018). There is no national data on firstgeneration college students who participate in education abroad. Our findings counter the implicit deficit-based narrative of study abroad as a way to help marginalized students "catch up with" their non-first-generation or non-Latinx peers in terms of social and cultural capital.

Our research findings suggest many implications for practice that include a more intentional approach to recognizing and rewarding CCW-related capital that students possess in the advising, application, and preparation processes for education abroad. We believe that this research underscores the importance of strengths-based pedagogies in teaching abroad and we recommend that international educators ensure they incorporate them into their programs and courses. In these ways, we can increase the likelihood that first-generation, Latinx students, as well as other underrepresented students, participate in powerful educational experiences, which are built to reinforce their existing strengths as well as to offer new opportunities for further development. In the words of Rendón (1994), we believe that international educators have both the responsibility and opportunity to "harness that strength, and . . . unleash the creativity and exuberance for learning that is present in all students who feel free to learn, free to be who they are, and validated for what they know and believe." By validating (Rendón, 1994) first-generation Latinx students' inherent assets (Yosso, 2005) throughout the education abroad process, we can best support their holistic growth, development, and liberation in pursuit of social justice and equity in education.

\section{References}

Anderson, E. C. (2005). Strengths-based educating: A concrete way to bring out the best in students - and yourself: The confessions of an educator who got it right-finally! Educational Horizons, 83(3), 180-189.

Barlow, C. A. (2007). In the third space: A case study of Canadian students in a social work practicum in India. International Social Work, 50, 243-254. doi:10.1177/00208728070 73990

Bathurst, L., \& LaBrack, B. (2012). Shifting the locus of intercultural learning: Intervening prior to and after student experiences abroad. In: M. Vande Berg, R. M. Paige, and K. H. Lou (Eds.), Student learning abroad: What our students are learning, what they're not, and what we can do about it. 261-283. Sterling, VA: Stylus Publishing.

Bennett, J. M. (Ed.). (2015). The Sage encyclopedia of intercultural competence. Thousand Oaks, CA: Sage Publications. 
Berdan, S., Goodman, A., \& Taylor, C. (2013). A student guide to study abroad. New York, NY: AIFS Foundation and Institute of International Education.

Chieffo, L., \& Griffiths, L. (2004). Large-scale assessment of student attitudes after a short-term study abroad program. Frontiers: The Interdisciplinary Journal of Study Abroad, 10, 165-177.

de Brey, C., Musu, L., McFarland, J., Wilkinson-Flicker, S., Diliberti, M., Zhang, A., Branstetter, C., \& Wang, X. (2019). Status and trends in the education of racial and ethnic groups 2018 (NCES 2019038). U.S. Department of Education. Washington, DC: National Center for Education Statistics. Retrieved October 29, 2019 from https://nces.ed.gov/ pubsearch/

DeRosa, E., \& Dolby, N. (2014). "I don't think the university knows me.”: Institutional culture and lowerincome, first-generation college students. InterActions: UCLA Journal of Education and Information Studies, 10(2).

Engel, L.C. (2017). Underrepresented students in study abroad: Investigating impacts. Washington, DC: Institute for International Education.

Farrugia, C.A., \& Sanger, J. (2017). Gaining an employment edge: The impact of study abroad on 21st century skills and career prospects in the United States. New York, NY: Institute for International Education.

Freire, P. (1986). Pedagogy of the oppressed. New York, NY: Continuum.

Guerrero, E. (2006). The road less traveled: Latino students and the impact of studying abroad. (Doctoral dissertation.) University of California, Los Angeles, California. Retrieved from Dissertation Abstracts International. (AAT 3249418)

Hammer, M. R., Bennett, M., \& Wiseman, R. (2003). Measuring intercultural sensitivity: The intercultural development inventory. International Journal of Intercultural Relations, 27(4), 421-443.

Institute of International Education (IIE). (2018). Profile of U.S. study abroad students, 2004/05 2016/2017. Open Doors report on international educational exchange. Retrieved on October 29, 2019 from https://www.iie.org/Research-and-Insights/Open-Doors/Data/US-Study-Abroad/StudentProfile.

Jackson, M. J. (2006). Traveling shoes: Study abroad experiences of African American students participating in California State University international programs. (Doctoral dissertation.) University of San Francisco, San Francisco, California. Retrieved from ProQuest Dissertations and Theses. (UMI No. 3227519)

Jehangir, R., Williams, R., \& Jeske, J. (2012). The influence of multicultural learning communities on the intrapersonal development of first-generation college students. Journal of College Student Development, 53(2): 267-284. doi:10.1353/csd.2012.0035

Kolb, D. A. (1984). Experiential learning: Experience as the source of learning and development (Vol. 1). Englewood Cliffs, NJ: Prentice-Hall.

Kouyoumdjian, C., Guzmán, B. L., Garcia, N. M., \& Talavera-Bustillos, V. (2017). A community cultural wealth examination of sources of support and challenges among Latino first- and second-generation college students at a Hispanic serving institution. Journal of Hispanic Higher Education, 16(1): 6176. doi:10.1177/1538192715619995

Kuh, G. D. (2008). High-impact educational practices: What they are, who has access to them, and why they matter (excerpt). Association of American Colleges and Universities. Retrieved from https://www.voced.edu.au/content/ngv\%3A54014

Ladson-Billings, G. 2014. Culturally relevant pedagogy 2.0: a.k.a. the remix. Harvard Educational Review, 84(1): 74-84. doi:10.17763/haer.84.1.p2rj131485484751

Landau, J., \& Moore, D. C. (2001). Towards reconciliation in the motherland: Race, class, nationality, gender, and the complexities of American student presence at the University of Legon. Frontiers: The Interdisciplinary Journal of Study Abroad, 7: 25-59. Retrieved from http://www.frontiersjournal.com/back/seven/volseven.html

Lincoln, Y. S., \& Guba, E. G. (1985). Naturalistic inquiry. Beverly Hills, CA: Sage.

Lopez, S., \& Louis, M. (2009). The principles of strengths-based education. Journal of College \& Character, 10(4). doi: 10.2202/1940-1639.1041 
Mapp, S. C. (2012). Effect of short-term study abroad programs on students' cultural adaptability. Journal of Social Work Education, 48(4), 727-737.

Martin, K., Galentino, R., \& Townsend, L. (2014). Community college student success: The role of motivation and self-empowerment. Community College Review, 42(3): 221-241.

Morgan, R. M., Mwegelo, D. T., \& Turner, L. N. (2002). Black women in the African diaspora seeking their cultural heritage through studying abroad. NASPA Journal, 39, 333-353. doi:10.2202/19496605.1175

Onwuegbuzie, A. J., \& Leech, N. L. (2007). Validity and qualitative research: An oxymoron? Quality and Quantity, 41(2): 233-249. doi:10.1007/s11135-006-9000-3

Padgett, R. D., Johnson, M. P., \& Pascarella, E. T. (2012). First-generation undergraduate students and the impacts of the first year of college: Additional evidence. Journal of College Student Development, 53(2): 243-266. doi:10.1353/csd.2012.0032

Pascarella, E. T., Pierson, C. T., Wolniak, G. C., \& Terenzini, P. T. (2004). First-generation college students: Additional evidence on college experiences and outcomes. The Journal of Higher Education, 75(3): 249-284. doi:10.1080/00221546.2004.11772256

Raby, R. L., Rhodes, G. M., \& Biscarra, A. (2014) Community college study abroad: Implications for student success, Community College Journal of Research and Practice, 38(2-3), 174-183. doi:10.1080/10668926.2014.851961

'Rausch, K. 2017. First-generation strength: Supporting first-generation college students in study abroad. (Doctoral dissertation.) Arizona State University, Tempe, Arizona. Retrieved from https://repository.asu.edu/attachments/186534/content/Rausch_asu_0010E_16882.pdf .

Raymondi, M. D. (2005). Latino students explore racial and ethnic identity in a global context. (Doctoral dissertation.) State University of New York at Binghamton, New York. Retrieved from Dissertation Abstracts International. (AAT 3153765)

Rendón, L. I. (1994). Validating culturally diverse students: Toward a new model of learning and student development. Innovative higher education, 19(1): 33-51. doi:10.1007 /BF01191156

Rendón, L.I., (2009). Sentipensante (sensing/thinking) pedagogy: Educating for wholeness, social justice and liberation. Sterling, VA: Stylus.

Rossman, G. B., \& Rallis, S. F. (2016). An introduction to qualitative research: Learning in the field. Thousand Oaks, CA: Sage Publications.

Saldaña, J. (2016). The coding manual for qualitative researchers. Thousand Oaks, CA: Sage Publications.

Shedivy, S. L. (2004). Factors that lead some students to continue the study of foreign language past the usual 2 years in high school. System, 32(1): 103-119. doi:10.1016/j.system.2003.09.008

Solórzano, D. G. (1998). Critical race theory, race and gender microaggressions, and the experience of Chicana and Chicano scholars. International Journal of Qualitative Studies in Education, 11(1): 121136. doi:10.1080/095183998236926

Solórzano, D. G., Villalpando, O., \& Oseguera, L. (2005). Educational inequities and Latina/o undergraduate students in the United States: A critical race analysis of their educational progress. Journal of Hispanic Higher Education. 4(3): 272-294. doi:10. 1177/11538192705276550

Soria, K. M., \& Stubblefield, R. (2015). Knowing me, knowing you: Building strengths awareness, belonging, and persistence in higher education. Journal of College Student Retention: Research, Theory and Practice, 17(3): 351-372. doi.10.1177/1521025115 575914

Stebleton, M., Soria, K., \& Cherney, B. (2013). The high impact of education abroad: College students' engagement in international experiences and the development of intercultural competencies. Frontiers: The International Journal of Study Abroad, 22, 1-24.

Stephens, N. M., Fryberg, S.A., Markus, H. R., Johnson, C.S., \& Covarrubias, R. (2012). Unseen disadvantage: How American universities' focus on independence undermines the academic performance of first-generation college students. Journal of Personality and Social Psychology, 102(6), 1178-1197. doi:10.1037/a0027143 
Sutton, R. C., \& Rubin, D. L. (2010, Jun.). Documenting the academic impact of study abroad: Final report of the GLOSSARI project. Retrieved 4/26/2013 from http://glossari.uga.edu/datasets/pdfs/FINAL.pdf

Teranishi, C. S. (2007). Impact of experiential learning on Latino college students' identity, relationships, and connectedness to community. Journal of Hispanic Higher Education, 6(1), 52-72. doi: $10.1177 / 1538192706294946$

Teranishi, C. S., \& Hannigan, T. P. (2008). Impact of study abroad on Latino/a college students' ethnic identity and cross-cultural adaptability. Multicultural Learning and Teaching, 3(1): 52-67. doi:10.2202/2161-2412.1029

Tran, V. C. (2010). English gain vs. Spanish loss? Language assimilation among second-generation Latinos in young adulthood. Social Forces, 89(1), 257-284.

Trujillo, S. A. (2017, December 11). Beyond barriers: Re-thinking education abroad using a strengthsbased approach. Retrieved from https://www.diversitynetwork.org/news/378185/Beyond-BarriersRe-Thinking-Education-Abroad-Using-a-Strengths-Based-Approach.htm

Urdang, E. (2010). Awareness of self-a critical tool. Social Work Education, 29, 523-538. doi:10.1080/02615470903164950

Valenzuela, A. (1999). Subtractive schooling: U.S.-Mexican youth and the politics of caring. Albany, NY: Suny Press.

Valenzuela, A. (2002). Reflections on the subtractive underpinning of education research and policy. Journal of Teacher Education, 53(3), 235-241. doi:10.1177/0022487 102053003007

Vande Berg, M., Paige, R. M., \& Lou, K. H. (2012). Student learning abroad: What our students are learning, what they're not and what we can do about it, 3-28. Sterling, VA: Stylus.

VeLure Roholt, R., \& Fisher, C. (2013). Expect the unexpected: International short-term study course pedagogies and practices. Journal of Social Work Education, 49, 48-65. doi:10.1080/10437797.2013.755416

Villalpando, O. (2004). Practical considerations of critical race theory and Latino critical theory for Latino college students. New Directions for Student Services, 105, 41-50. doi:10. 1002/ss.115

Waldrep, J. C. (2017). Transforming education abroad for first-generation students: Leadership, student voice, and policy change. (Doctoral dissertation.) San Francisco State University, San Francisco, California). Retrieved from ProQuest Dissertations and Theses.

Wick, D. (2011). Study abroad for students of color: A third space for negotiating agency and identity. (Doctoral dissertation.) San Francisco State University, San Francisco, California. Retrieved from https://diva.sfsu.edu/users/eddsfsu/courses/dissertations

Willis, T. Y. (2012). Rare but there: An intersectional exploration of the experiences and outcomes of Black women who studied abroad through community college programs. (Doctoral dissertation.) California State University, Long Beach, California. Retrieved from ProQuest Dissertations and Theses. (Accession Order No. 3533746)

Willis, T. Y. (2015). And still we rise: Microaggressions and intersectionality in the study abroad experiences of Black women from community colleges. Frontiers: The Interdisciplinary Journal of Study Abroad, 26, 209-230.

Willis, T. Y. (2016). Microaggressions and intersectionality in the experiences of Black women studying abroad through community colleges: Implication for practice. In R. Raby \& E. Valeau (Eds.), International education at community colleges: From optional to integral (pp.127-142). New York, NY: Palgrave, Macmillan.

Willis, T. Y., Wick, D., Bykowski, C., Doran, J. K., Li, H. Y., \& Tran, A. (2019). Studying human trafficking in Thailand increases EPAS competencies and compels action at home. Journal of Social Work Education doi:10.1080/10437797.2019.1661901

Willis, T. Y., Wick, D., Han, T., Rivera, J. \& Doran, J. K. (2019). "If I did it over there, I can do it here": U.S. Latinx social work students in Costa Rican service placements deepening their professional identity and skills. Journal of Social Work Education, doi:10.1080/10437797.2019.1611513 
Yosso, T. J. (2005). Whose culture has capital? A critical race theory discussion of community cultural wealth. Race Ethnicity and Education, 8(1), 69-91.

Zull, J. E. (2012). The brain, learning and study abroad. In M. Vande Berg, R. M. Paige, \& K. H. Lou (Eds.), Student learning abroad: What our students are learning, what they're not, and what we can do about it (pp. 162-187). Sterling, VA: Stylus. 